\title{
Twin reversed arterial perfusion sequence in a monochorionic monoamniotic twin pregnancy: a very rare condition
}

\author{
Abolfazl Abouie', Nima Rakhshankhah', Ladan Younesi², Zeinab Safarpour², Ayda Roostaee ${ }^{2}$ \\ and Ghazaleh Amjad ${ }^{2 *}$
}

\begin{abstract}
Background: Twin reversed arterial perfusion sequence (TRAP) is a very rare congenital anomaly. We present sonographic findings of TRAP sequence in the case of a multiparous woman with a monochorionic monoamniotic twin pregnancy who was referred to our unit for blood sugar control.

Case presentation: The patient had a history of co-twin demise at 13 weeks of gestation without appropriate fetal surveillance afterwards. We found a monochorionic placentation with a normal appearing pump twin, an abnormal appearing co-twin without obvious cardiac activity and reversed arterial flow toward instead of away from the anomalous acardiac fetus. Therefore, the sonographic diagnosis of TRAP sequence was confirmed.
\end{abstract}

Conclusions: We recommend considering the potential rare complications of monochorionic twin pregnancy which necessitates proper surveillance and intervention to monitor suitable growth of pump twin.

Keywords: Case report, TRAP sequence, Monochorionic monoamniotic, Twin pregnancy, Ultrasound

\section{Background}

TRAP sequence is a very rare congenital anomaly that occurs in $1 / 35,000$ births [1]. This syndrome appears in nearly $1 \%$ of monochorionic twin pregnancy, with approximately $75 \%$ in diamniotic and $25 \%$ in monoamniotic twin pairs. Aberrant arterioarterial anastomosis in the single placenta accounts for specific complications in monochorionic twins [2]. In TRAP sequence, deoxygenated arterial blood pumps from pump twin to acardiac twin. Thus, in acardiac twin, lower structures have blood circulation and upper structures do not develop properly [3]. According to Malone classification [4], there are two kinds of twin in TRAP sequence which describe as hemicardius (imperfectly formed heart) and holoacardius (absence of heart). According to Joseph C classification, acardiac fetus categorises into acardius anceps (partially

\footnotetext{
*Correspondence: ghazal_1986_amjad@yahoo.com

${ }^{2}$ Shahid Akbarabadi Clinical Research Development Unit (ShACRDU), Iran

University of Medical Sciences (IUMS), Tehran, Iran

Full list of author information is available at the end of the article
}

developed head and face), acardius acephalus (no cephalic structures), acardius acormus (there is a head but no body) and acardius amorphous (no recognizable organs) [5]. In this case report, we present sonographic findings of a very rare case of TRAP sequence in monochorionic monoamniotic twin pregnancy.

\section{Case presentation}

A 22-year-old multiparous pregnant woman with gravida three, para one, living one and with a past history of one spontaneous abortion at 16 years of age was referred at 24 weeks of gestation to our tertiary obstetric and perinatology center for blood sugar control and fetal demise of one of the twins at 13 weeks of gestation. The patient had $\mathrm{O}+$ blood group and medical history of hypothyroidism (consuming $50 \mu \mathrm{g}$ of levothyroxine daily) and gestational diabetes which had been controlled by dietary recommendations. The patient was asymptomatic at presentation, and laboratory studies 


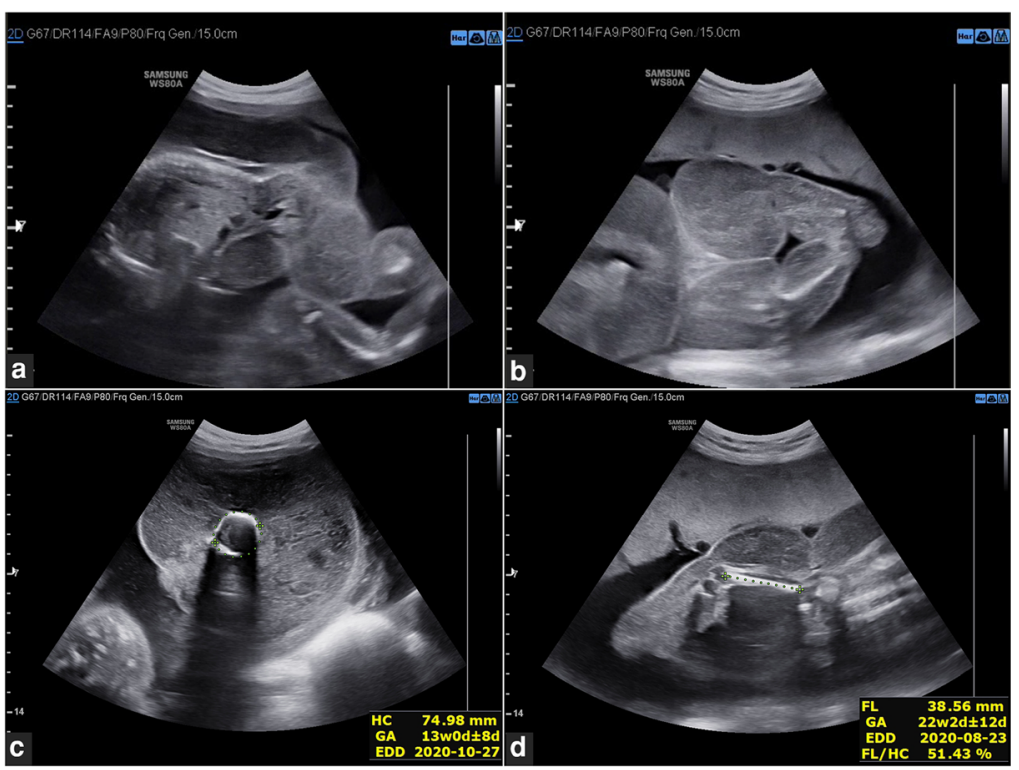

Fig. 1 a, b Dysmorphic acardiac fetus with diffuse soft tissue edema more severely in lower extremities. Marked growth discrepancy between HC and $\mathrm{FL}$ of acardiac twin is presented in $\mathbf{c}$ and $\mathbf{d}$

such as blood count, coagulation status, biochemistry and urine analysis were all normal.

Abdominal ultrasonography showed intrauterine twin pregnancy with an anterior placenta without obvious membrane in favor of monochorionic monoamniotic twin pregnancy. The twin at the right side of uterine cavity represented cardiac activity and normal appearance, and the one at the left side was dysmorphic without detectable fetal heart activity (Fig. 1). The viable twin showed normal morphology and growth consistent with 24 weeks of gestation and normal fetal Doppler parameters (Fig. 2). In fetal echocardiography, no obvious structural cardiac anomaly was present. However, mild cardiomegaly and tricuspid regurgitation (TR) were evident. In addition, polyhydramnios with deepest fluid pocket (DFP) of $10.5 \mathrm{~cm}$ was evident of cardiac function failure (Fig. 3). On further examination of acardiac twin, a small and deformed skull with head circumference (HC) of $75 \mathrm{~mm}$ (equivalent to 13 weeks of gestation) was observed. Remarkable diffuse soft tissue edema was seen around the fetus with an average thickness of 33 $\mathrm{mm}$, which was more severe in the lower limbs. The femoral length (FL) was $38 \mathrm{~mm}$ (compatible with 22 weeks of gestation) that represented lower extremity development in comparison with unrecognizable head, trunk and upper extremities (Fig. 1). Pulsed Doppler study of umbilical cord revealed reversed arterial flow toward rather than away from the anomalous fetus. Single umbilical artery also was obvious (Fig. 3). These ultrasound findings were all consistent with twin reversed arterial perfusion (TRAP) sequence in a monochorionic monoamniotic twin pregnancy. Three days

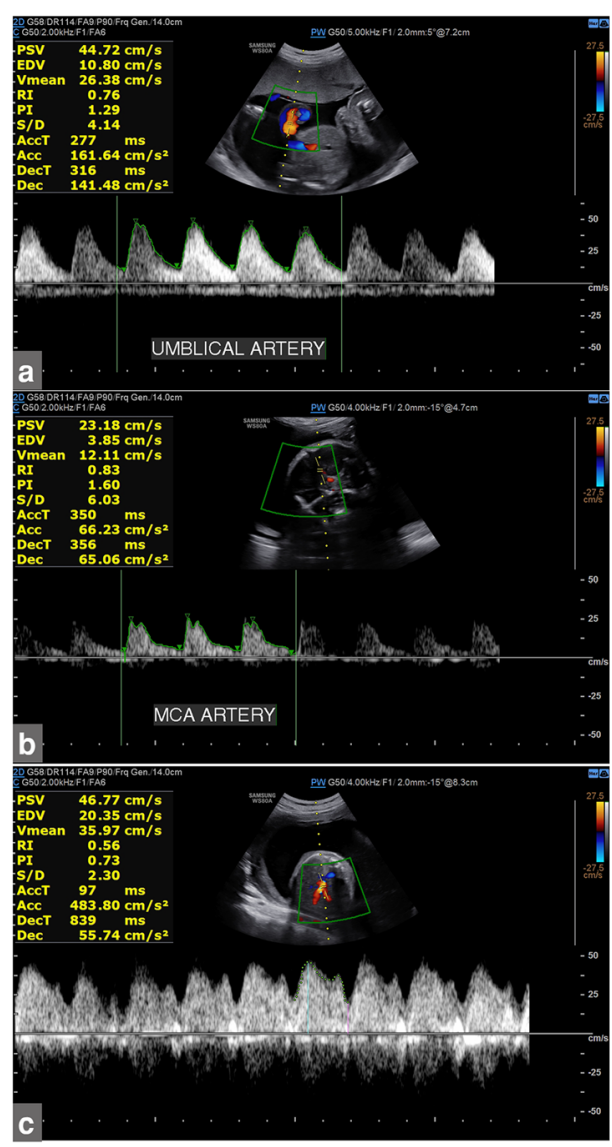

Fig. 2 Normal fetal Doppler parameters such as umbilical artery (a), middle cerebral artery (b) and ductus venosus (c) in pump twin 


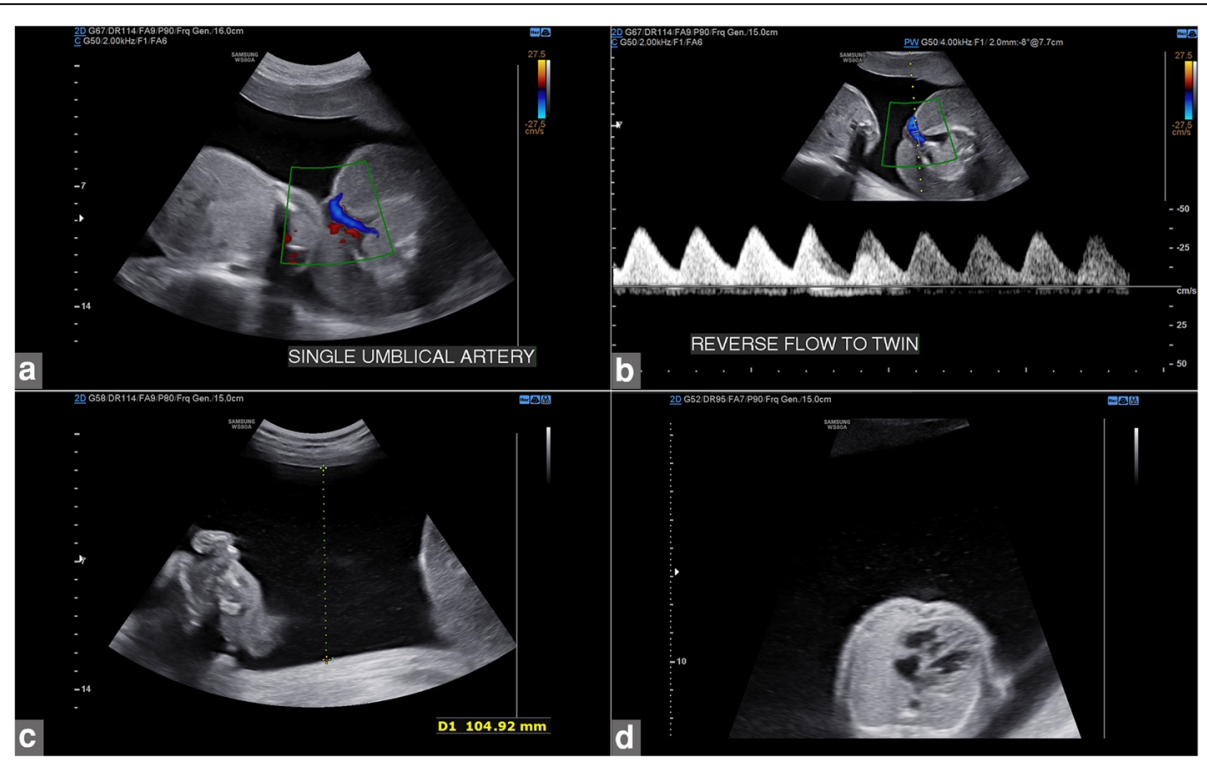

Fig. 3 Single umbilical artery (a) with reversed flow to the acardiac fetus at pulsed Doppler study (b). Polyhydramnios (c) and mild cardiomegaly (d) in pump twin are signs of altered fetal heart function

later, the patient was referred with the complaint of rupture membrane, and cardiac activity was absent in both twins in ultrasonography.

\section{Conclusions}

The sonographic appearance of acardiac twin may differ in many cases, but a hydropic fetus without cardiac activity is the main manifestation of TRAP sequence. Reversed arterial flow in the umbilical artery from pump twin to acardiac twin is revealed in spectral Doppler examination [6]. Furthermore, most acardiac twin presents umbilical artery malformations, and according to Roberto Ruiz-Cordero, 78\% of acardiac twin shows single umbilical artery and in $22 \%$ of cases, three vessel umbilical cord with thrombosis is described [7]. In majority of cases, pump twin develops high cardiac output failure including cardiomegaly, pericardial effusion and tricuspid regurgitation with polyhydramnios. Therefore, echocardiography is mandatory for the assessment and surveillance of cardiac function in pump twin [8]. The perinatal mortality of pump twin has been reported to range from 35 to $55 \%$ [9]. In our case, the pump twin demonstrated normal structural development. However, some degrees of cardiomegaly and mild tricuspid regurgitation in echocardiography and polyhydramnios were found, all of which were considered as a looming threat of fetal demise. All the abovementioned criteria associated with excessive volume of the acardiac twin predicted poor pregnancy outcome.

Intrauterine fetal demise and intra-amniotic or placental tumours such as placental teratoma should be considered as the differential diagnosis for TRAP sequence.
However, precise evaluation of spinal development and umbilical cord attachment can be beneficial for differentiation [8].

There is a variety of treatment modalities which can improve perinatal survival. In minimally invasive techniques, vascular anastomosis is interrupted by alcohol, diathermy, cord embolization or coagulation, laser therapy or radiofrequency ablation [10]. Eventually, the most crucial component in treatment is likely to detect this complication early in pregnancy and perform appropriate interventions before detrimental consequences occur.

\section{Abbreviations}

TRAP sequence: Twin reversed arterial perfusion sequence; HC: Head circumference; FL: Femoral length

\section{Acknowledgements}

Not applicable.

\section{Authors' contributions}

The authors have read and approved the final manuscript. All authors made a significant contribution to this study as mentioned below: AA: Data interpretation, writing the draft, discussion. NR: Data interpretation, writing the draft, discussion. LY: Study design, data collection, quality control. ZS: Study design, data collection, quality control. AR: Study design, data collection, quality control. GA: Study design, data interpretation, discussion.

\section{Funding}

Not applicable.

\section{Availability of data and materials}

The datasets used during the current report are available from the corresponding author on reasonable request.

Ethics approval and consent to participate

The patient included in this study gave written informed consent to participate in this report. 


\section{Consent for publication}

Written informed consent to publish this information was obtained from study participant.

\section{Competing interests}

The authors have no conflict of interests.

\section{Author details}

'Department of Radiology, Iran University of Medical Sciences (IUMS), Tehran, Iran. ${ }^{2}$ Shahid Akbarabadi Clinical Research Development Unit (ShACRDU), Iran University of Medical Sciences (IUMS), Tehran, Iran.

Received: 1 September 2020 Accepted: 2 November 2020

Published online: 18 November 2020

\section{References}

1. Hartge D, Weichert J (2012) Prenatal diagnosis and outcome of multiple pregnancies with reversed arterial perfusion (TRAP-sequence). Arch Gynecol Obstet 286(1):81-88

2. Chalouhi G, Stirnemann J, Salmon L, Essaoui, Quibel, Ville (2010) Specific complications of monochorionic twin pregnancies: twin-twin transfusion syndrome and twin reversed arterial perfusion sequence. Semin Fetal Neonatal Med 15:349-356

3. Van Allen, Smith, Shepard T (1983) Twin reversed arterial perfusion (TRAP) sequence: a study of 14 twin pregnancies with acardius. Semin Perinatol 7: 285-293

4. Malone F, D'Alton M (2000) Anomalies peculiar to multiple gestations. Clin Perinatol 27(4):1033-1046

5. Sommerfeldt JC, Putnins R, Fung KFK, Grynspan D et al (2014) AIRP best cases in radiologic-pathologic correlation: twin reversed arterial perfusion sequence. RadioGraphics. 34(5):1385-1390

6. James W (1977) A note on the epidemiology of acardiac monsters. Teratology. 16:162-211

7. Ruiz-Cordero R, Birusingh R, Pelaez L, Azouz M, Rodriguez M (2016) Twin reversed arterial perfusion sequence (TRAPS): an illustrative series of 13 cases. Fetal Pediatr Pathol 35(2):63-80

8. Malone F, D'Alton. Chapter 38: Multiple gestation: clinical characteristics and management. In Creasy, Resnik R, lams J, Lockwood C, Thomas M, Greene M. Creasy and Resnik's maternal-fetal medicine: principles and practice. Philadelphia: Elsevier/Saunders; 2014. p. 578-596e4.

9. Moore T, Gale S, Benirschke K (1990) Perinatal outcome of forty nine pregnancies complicated by acardiac twinning. Am J Obstet Gynecol 163: 907-912

10. Pagani G, D'Antonio F, Khalil A, Papageorghiou A, Bhide A, Thilaganathan B (2013) Intrafetal laser treatment for twin reversed arterial perfusion sequence: cohort study and meta-analysis. Ultrasound Obstet Gynecol 42(1): $6-14$

\section{Publisher's Note}

Springer Nature remains neutral with regard to jurisdictional claims in published maps and institutional affiliations.

\section{Submit your manuscript to a SpringerOpen ${ }^{\circ}$ journal and benefit from:}

- Convenient online submission

- Rigorous peer review

- Open access: articles freely available online

High visibility within the field

- Retaining the copyright to your article

Submit your next manuscript at $\boldsymbol{\nabla}$ springeropen.com 